\title{
Landscape of somatic allelic imbalances and copy number alterations in HER2-amplified breast cancer
}

Johan Staaf ${ }^{1,2 *}$, Göran Jönsson ${ }^{1,2}$, Markus Ringnér ${ }^{1,2}$, Bo Baldetorp ${ }^{1}$ and Åke Borg ${ }^{1,2,3}$

\begin{abstract}
Introduction: Human epidermal growth factor receptor 2 (HER2)-amplified breast cancer represents a clinically well-defined subgroup due to availability of targeted treatment. However, HER2-amplified tumors have been shown to be heterogeneous at the genomic level by genome-wide microarray analyses, pointing towards a need of further investigations for identification of recurrent copy number alterations and delineation of patterns of allelic imbalance.
\end{abstract}

Methods: High-density whole genome array-based comparative genomic hybridization $(\mathrm{aCGH})$ and single nucleotide polymorphism (SNP) array data from 260 HER2-amplified breast tumors or cell lines, and 346 HER2negative breast cancers with molecular subtype information were assembled from different repositories. Copy number alteration (CNA), loss-of-heterozygosity $(\mathrm{LOH})$, copy number neutral allelic imbalance (CNN-Al), subclonal CNA and patterns of tumor DNA ploidy were analyzed using bioinformatical methods such as genomic identification of significant targets in cancer (GISTIC) and genome alteration print (GAP). The patterns of tumor ploidy were confirmed in 338 unrelated breast cancers analyzed by DNA flow cytometry with concurrent BAC aCGH and gene expression data.

Results: A core set of 36 genomic regions commonly affected by copy number gain or loss was identified by integrating results with a previous study, together comprising > 400 HER2-amplified tumors. While CNN-Al frequency appeared evenly distributed over chromosomes in HER2-amplified tumors, not targeting specific regions and often $<20 \%$ in frequency, the occurrence of LOH was strongly associated with regions of copy number loss. HER2-amplified and HER2-negative tumors stratified by molecular subtypes displayed different patterns of LOH and CNN-Al, with basal-like tumors showing highest frequencies followed by HER2-amplified and luminal B cases. Tumor aneuploidy was strongly associated with increasing levels of LOH, CNN-Al, CNAs and occurrence of subclonal copy number events, irrespective of subtype. Finally, SNP data from individual tumors indicated that genomic amplification in general appears as monoallelic, that is, it preferentially targets one parental chromosome in HER2-amplified tumors.

Conclusions: We have delineated the genomic landscape of CNAs, amplifications, LOH, and CNN-AI in HER2amplified breast cancer, but also demonstrated a strong association between different types of genomic aberrations and tumor aneuploidy irrespective of molecular subtype.

\footnotetext{
* Correspondence: johan.staaf@med.lu.se

'Department of Oncology, Clinical Sciences, Lund University and Skåne

University Hospital, Barngatan 2B, SE 22185 Lund, Sweden

Full list of author information is available at the end of the article
} 


\section{Introduction}

Breast cancer $(\mathrm{BC})$ constitutes a heterogeneous group of lesions with differences in clinical presentation, pathological features and biological behavior. Amplification and overexpression of the human epidermal growth factor receptor 2 (HER2) (HER2/neu, ERBB2) oncogene occur in 15 to $25 \%$ of invasive $\mathrm{BC}[1,2]$ and define a clinically important subgroup (HER2+). Patients with HER2+ BC have traditionally been associated with poor prognosis $[1,3]$; however, the advent of HER2-targeted therapies has changed the natural course of the disease for many patients, representing one of the success stories of modern oncology. Unfortunately, not all patients with HER2 + disease benefit from targeted treatment, and some develop treatment resistance over time. It has become evident through microarray-based studies that $\mathrm{BC}$ with genomic amplification of HER2 (HER2-amplified) constitutes a biologically heterogeneous subgroup of tumors regarding both gene expression patterns and copy number alterations (CNAs) [4,5]. Such genomic profiles have predominantly been obtained from array comparative genomic hybridization (aCGH) [5-7], but more recently single nucleotide polymorphism (SNP) microarrays have become increasingly used, allowing simultaneous detection of both CNAs and allelic imbalance (AI) [8-11]. However, due to disease and data complexity, CNA information has so far mostly been extracted from SNP array data and only recently have robust analysis methods emerged capable of detecting and integrating CNAs and AI [10,12-14]. Consequently, HER2-amplified BC has not yet been thoroughly investigated in this respect. We, therefore, analyzed assembled BC data from different repositories and by integrating these results with our previous study comprising 200 HER2-amplified tumors [5], we were able to define a core set of significant CNAs and recurrent amplifications. Furthermore, using a combination of bioinformatical methods for SNP arrays and quantitative DNA flow cytometry (FCM) we delineated the patterns of loss of heterozygosity $(\mathrm{LOH})$, copy number neutral allelic imbalance (CNN-AI), tumor ploidy, tumor subclonality and occurrence of monoallelic gene amplification. Data from HER2-amplified tumors were compared to data from other subgroups of $\mathrm{BC}$, shedding light on a complex landscape of genomic alterations in a clinically important disease entity.

\section{Materials and methods Tumor material}

DNA from 26 frozen tumors with HER2 gene amplification was extracted as previously described [5]. SNP analysis was performed at the SCIBLU Genomics Resource Center [15] using the Illumina (Illumina, San Diego, CA, USA) Omni $1 \mathrm{M}$ and 2.5 M Quad beadchips $(n=5$ and 21 , respectively) according to manufacturer's instructions. The 26 cases are referred to as the LundHER2-SNP set and are part of a previous study of HER2-amplified BC that was approved by the regional Ethical Committee in Lund (reg. no. LU240-01 and 2009/658), waiving the requirement for informed consent for the study [5]. In addition, genomic profiles were obtained from public repositories for 12 studies [8-11,16-23] comprising 218 primary tumors with amplification of HER2, and 16 reported HER2-amplified BC cell lines analyzed by Agilent (Agilent, Santa Clara, CA, USA) aCGH, Illumina SNP beadchips or Affymetrix (Affymetrix, Santa Clara, CA, USA) SNP arrays [. HER2amplified tumor cases were identified based on genomic profiles and displayed marked elevation of HER 2 copy number $(\mathrm{CN})$ estimates compared to remaining samples from respective data set (Figure S1, Additional file 1). Additionally, 115 of the 218 tumors had public annotations regarding HER2-status, and of these 98\% (113) were annotated as HER $2+$. Gene expression profiles were available for 99 of 218 tumor cases. Gene expression subtypes were assigned based on correlation to PAM50 [24] gene expression centroids obtained from Weigelt et al. [25] as further described (Additional file 2 and [26]). Correlation of gene expression data with genomic alterations was performed as described ([27] and Additional file 2). Analysis of differential gene expression for genes in recurrent amplifications was performed as described (Additional file 2). Patient and tumor characteristics are summarized in Table 1 and Table S1 in Additional file 1. SNP data for the LundHER2-SNP set are available as series GSE31645 from Gene Expression Omnibus [28].

\section{SNP and aCGH preprocessing}

Affymetrix SNP array data for 108 HER2-amplified tumors or cell lines were obtained from public repositories $[17,28]$. CEL files were normalized using CRMAv2 [29] and ACNE [30] for generation of $\mathrm{CN}$ and B allele frequency (BAF) estimates as further described (Additional file 2). CN and BAF estimates for 47 HER2-amplified cases analyzed by Illumina SNP beadchips were generated using GenomeStudio (Illumina). Illumina 2.5M SNP BAF data were quantile normalized [21] prior to further analysis. Normalized Agilent $244 \mathrm{~K}$ data were obtained for 105 HER2-amplified cases from Gene Expression Omnibus [28]. Genomic profiles from all array platforms except the Illumina $2.5 \mathrm{M}$ platform and GSE17907 were partitioned using Gain and Loss Analysis of DNA (GLAD) [31]. The Illumina 2.5 M platform was partitioned using Circular Binary Segmentation with $\alpha=0.001$ [32], while already partitioned data for GSE17907 were obtained from Gene Expression Omnibus. All genomic profiles were centralized similarly as described [18]. Probe annotations for all array platforms 
Table 1 Characteristics of individual data sets used in the present study stratified by microarray platform

\begin{tabular}{|c|c|c|c|c|c|c|c|c|c|c|}
\hline Data Set & \# HER2-amplified & Platform & $\mathrm{BAF}^{\mathrm{A}}$ & GISTIC/GAP ${ }^{B}$ & \# Cell lines & $\begin{array}{l}\text { Matching } \\
\text { GEX }\end{array}$ & $\begin{array}{l}\text { ER: } \\
-/+\end{array}$ & $\begin{array}{l}\text { LN C: } \\
-/+\end{array}$ & $\begin{array}{l}\text { Grade: } \\
1 / 2 / 3\end{array}$ & $\begin{array}{c}\mathrm{PR}{ }^{\mathrm{D}:} \\
-/+\end{array}$ \\
\hline GSE10099 [11] & 27 & Affymetrix 100K & Yes & Yes/Yes & 0 & 27 & $11 / 16$ & $25 / 0$ & $0 / 1 / 10$ & $11 / 12$ \\
\hline \multirow[t]{2}{*}{ GSE16619 [9] } & 11 & Affymetrix $250 \mathrm{~K} \mathrm{Nsp}$ & Yes & Yes/Yes & 0 & NA & $2 / 3$ & $3 / 8$ & $1 / 3 / 7$ & $4 / 1$ \\
\hline & 14 & Affymetrix 5.0 & No & Yes/No & 0 & NA & $5 / 5$ & $3 / 9$ & $0 / 3 / 11$ & $5 / 4$ \\
\hline Nikolsky [16] & 9 & Affymetrix 250K Sty & Yes & Yes/Yes & 0 & NA & NA & NA & NA & NA \\
\hline GSE19399 [17]* & 32 & Affymetrix 250K Sty & Yes & Yes/Yes & 6 & NA & NA & NA & NA & NA \\
\hline GSE7545 [8] & 5 & Affymetrix $250 \mathrm{~K} \mathrm{Nsp}$ & Yes & Yes/Yes & 0 & NA & $1 / 0$ & $0 / 5$ & NA & $1 / 0$ \\
\hline GSE13696 [22] & 6 & Affymetrix 100K & Yes & No/No & 6 & NA & NA & NA & NA & NA \\
\hline GSK [23] & 4 & Affymetrix $250 \mathrm{~K} \mathrm{Nsp}$ & Yes & No/No & 4 & NA & NA & NA & NA & NA \\
\hline Van Loo [10] & 20 & Illumina 109K & Yes & Yes/Yes & 0 & 20 & $14 / 6$ & $5 / 14$ & $0 / 7 / 13$ & NA \\
\hline GSE11977 [21] & 1 & Illumina 550K & Yes & Yes/Yes & 0 & NA & $0 / 1$ & $1 / 0$ & NA & $0 / 1$ \\
\hline GSE20393 [19] & 42 & Agilent 244K & No & Yes/No & 0 & NA & $2 / 1$ & NA & NA & $2 / 0$ \\
\hline GSE20394 [18] & 15 & Agilent 244K & No & Yes/No & 0 & 7 & $9 / 6$ & $5 / 10$ & 0/6/9 & $4 / 11$ \\
\hline GSE17907 [20] & 48 & Agilent 244K & No & Yes/No & 0 & 45 & $20 / 21$ & $12 / 27$ & $3 / 10 / 28$ & $23 / 18$ \\
\hline \multirow[t]{2}{*}{ Lund-HER2-SNP set } & 5 & Illumina 1M & Yes & No/No & 0 & NA & $4 / 1$ & $1 / 4$ & NA & $4 / 1$ \\
\hline & 21 & Illumina $2.5 \mathrm{M}$ & Yes & No/No & 0 & NA & $15 / 6$ & $13 / 8$ & NA & $16 / 5$ \\
\hline
\end{tabular}

were updated to the hg18 genome build [33]. Partitioned genomic profiles from different array platforms were merged to a common 10,000 bp probe set using a modified version of the method described by Gunnarsson et al. [34] (Additional file 2). Data processing steps are further described in Additional file 2.

\section{Identification of $\mathrm{Al}$ and significant CNAs}

A modified version of the BAF segmentation [12] software was used to partition BAF estimates from SNP arrays. Partitioned BAF estimates were subsequently integrated with $\mathrm{CN}$ data as described (Additional file 2). Genomic Identification of Significant Targets in Cancer (GISTIC) [35] analysis was used to identify significant CNAs using a residual q-value cut-off of 0.05 (Additional file 2). Only data from the 218 primary tumors obtained from public repositories were used in GISTIC analysis. Thus, HER2-amplified cell lines and the LundHER2-set were excluded from GISTIC analysis, the latter due to overlap with our previous study [5]. Recurrent high-level amplifications, excluding $17 \mathrm{q}$, were defined as the minimal overlap of amplifications with $\log 2$ ratio $>1$ occurring in $\geq 3 \%$ of the 218 samples. Recurrent high-level amplifications on $17 q$ were defined from GISTIC regions of gain on $17 q$ due to the high genomic complexity on this chromosome arm. The fraction of the genome altered by CNAs (CN-FGA) was defined as previously described [5].

\section{HER2-negative breast cancer SNP data set}

A HER2-negative $\mathrm{BC}$ reference SNP data set comprising 346 tumors was created by excluding HER2-amplified cases from the Van Loo [10] and GSE10099 [11] data sets. SNP array data were processed similarly as for HER2-amplified cases from respective data set. Gene expression data were available for all 346 cases, and samples were classified according to PAM50 gene expression subtypes (Table S1 in Additional file 1). Unclassified samples, and the few HER2-negative samples classified as belonging to the HER2-enriched molecular subtype in the reference data set were excluded from further analysis, leaving a final number of 308 cases used in subsequent comparisons. The 308 cases were classified as basal-like $(n=96)$, luminal A $(n=88)$, luminal B $(n=90)$, and normal-like $(n=34)$.

\section{GAP analysis}

Integrated $\mathrm{AI}$ and $\mathrm{CN}$ data for primary tumors analyzed by SNP arrays (99 HER2-amplified, 308 HER2-negative) merged to the 10,000 bp probe set were subjected to Genome Alteration Print (GAP) [13] analysis for estimation of allele-specific copy numbers, fraction of aberrant cells and an in silico tumor ploidy (referred to as GAPploidy hereon). Frequency of gains and losses from GAP profiles, relative to the GAP-ploidy, as well frequency of CNN-AI were calculated as described [10]. LOH frequency was defined as described [10] with the addition that $\mathrm{LOH}$ was not inferred for SNPs called as gain. The fraction of the genome altered by LOH (LOH-FGA) and CNN-AI (CNN-FGA) were defined similarly as for CNAs.

\section{Identification of subclonal CN loss events}

To estimate the frequency of subclonal $\mathrm{CN}$ events in HER2-amplified and HER2-negative tumors, only regions identified as $\mathrm{CN}$ loss relative to the GAP-ploidy 
were considered for further analysis. For each sample, a set of $\mathrm{CN}$ loss regions were identified by selecting loss regions for which the total GAP CN differed by $\geq 0.6$ from another $\mathrm{CN}$ loss region. This set of $\mathrm{CN}$ loss regions were filtered so that only regions with: 1) GLAD partitioned $\mathrm{CN} \log 2$ ratio $<-.12$, and 2) size > 100 markers remained. Finally, to reduce influence of small shifts in the data an absolute difference $>0.2$ in GLAD partitioned $\log 2$ ratios between the $\mathrm{CN}$ loss regions in the set with the highest and lowest GAP CNs, respectively, were required for the sample to be annotated as harboring subclonal $\mathrm{CN}$ loss.

\section{DNA flow cytometry analysis}

DNA FCM data for a cohort of 338 BC patients with available $\mathrm{BAC}$ aCGH and gene expression data (assembled from [5,36] and unpublished data) were obtained as previously described [37]. DNA histograms were evaluated using ModFitLT (Verity Software House, Topsham, ME, USA) as described [38]. An experimental tumor ploidy (FCM-ploidy) was calculated as the sum of each detected peak's DNA-index times the fraction of cells present in the peak, representing a measurement of the total amount of DNA in analyzed samples. Tissues from diploid tumor cases were verified by touch imprinting and subsequent HE staining to contain cancer cells. PAM50 molecular classifications and BAC aCGH data were available for 282 and 234 cases respectively. Patient and tumor characteristics for FCM analyzed cases are summarized in Table S1 in Additional file 1.

\section{Results}

Repeated observations of significant CNAs and recurrent amplifications in HER2-amplified breast cancer

GISTIC analysis of 218 primary HER2-amplified tumors profiled by high-density SNP or oligonucleotide aCGH identified 80 regions (34 gains and 46 losses) distributed across all autosomes (Figure 1A, Additional file 3). Of the 80 GISTIC regions, 17 overlapped with GISTIC regions identified in our previous study of 200 HER2amplified $\mathrm{BCs}$ profiled by BAC aCGH [5] using the same q-value threshold (Additional file 4). Moreover, an additional 19 GISTIC regions were located in close vicinity (< $2 \mathrm{Mbp}$ ) from previously identified GISTIC regions [5] (Additional file 4 and Figure S2A in Additional file 5). Taken together this highlights a core set of genomic regions commonly affected by CNAs in HER2amplified BC. Integration of gene expression data with $\mathrm{CN}$ estimates for genes in these core regions identified numerous genes with significant correlation between mRNA levels and $\mathrm{CN}$ estimates, of which some overlapped with findings from our previous BAC study (Additional file 4). The overall pattern of CNAs in HER2-amplified BC was mimicked in 16 HER2- amplified BC cell lines, although with slightly higher prevalence in cell lines, and with a few discrepancies, for example, more frequent losses on chromosome 2 in cell lines (Figure S2B in Additional file 5). The shortest region of amplification, including the complete HER2 gene, was delineated to 59,004 bp (chr17:3508759435146597, hg18 coordinates) comprising HER2, C17orf37, and parts of the PERLD1 gene (Figure S2C-E in Additional file 5). Notably, the shortest region of amplification overlap did not include GRB7, in contrast to two previous reports $[5,20]$.

Corroborating our previous findings using BAC aCGH [5], we found: 1) four GISTIC regions stratifying HER2amplified cases based on estrogen receptor (ER)-status of which two were in the same genomic regions identified by BAC aCGH (Figure S2F in Additional file 5), 2) no difference in CN-FGA between ER-negative and ERpositive tumors, 3) 14 recurrent high-level amplifications, excluding chromosome 17, of which eight overlapped directly or were in close proximity to BAC aCGH findings with similar frequencies (Additional file 6), and 4) similar frequency (19\%) of amplifications in the centromeric region of chromosome 17, (17p11.117q11.1, CEP17-amplification). Additionally, GISTIC was used to delineate the complex pattern of amplification on chromosome $17 q$, identifying nine regions of gain that all comprised cases with high-level amplification (Additional file 6). Of these nine regions, three overlapped directly with our previous BAC study, and two were in close proximity $(<500 \mathrm{kbp}$ ) (Additional file 6). Integration of gene expression data with $\mathrm{CN}$ estimates for genes in recurrent amplifications identified numerous genes with significant correlation between mRNA levels and $\mathrm{CN}$ estimates (Additional file 6). Notably, the majority of correlated genes were also found to be correlated in our previous study (Additional file 6). In combination with analysis of differential mRNA expression between amplified and non-amplified cases for a set of evaluable genes in the recurrent amplifications (Additional file 6), these analyses confirm the gene dosage dependence of specific genes recurrently amplified in HER2-amplified BC.

To investigate whether observed frequencies of $\mathrm{CN}$ gain and loss for the 218 cases were biased due to differences in tumor ploidy and aberrant cell content we calculated the frequency of $\mathrm{CN}$ gain and loss in relation to an in silico tumor ploidy (GAP-ploidy) for 99 cases analyzed by SNP arrays (Figure 1B). Reassuringly, we found a highly similar pattern of CNAs for these 99 cases (Figure 1B vs. Figure 1A). This finding is in contrast to a recent report using a similar bioinformatical approach in a smaller data set [10]. 
A

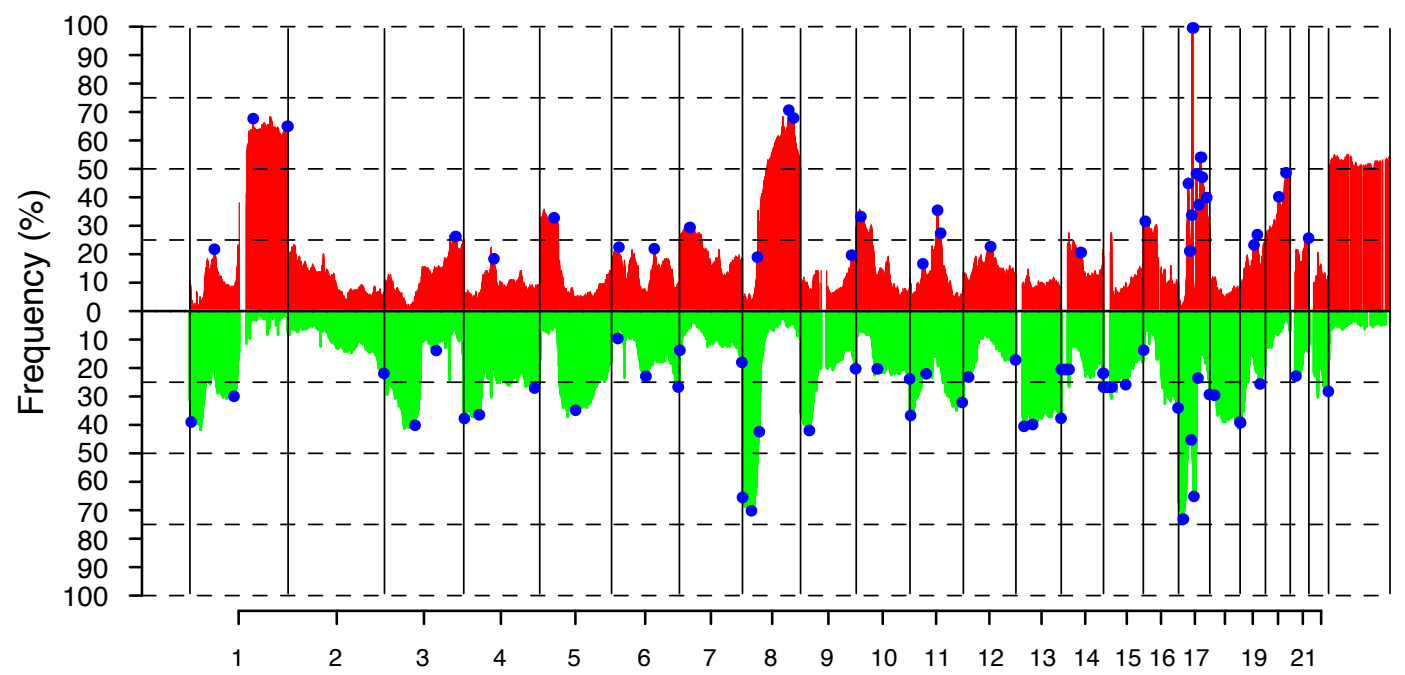

B

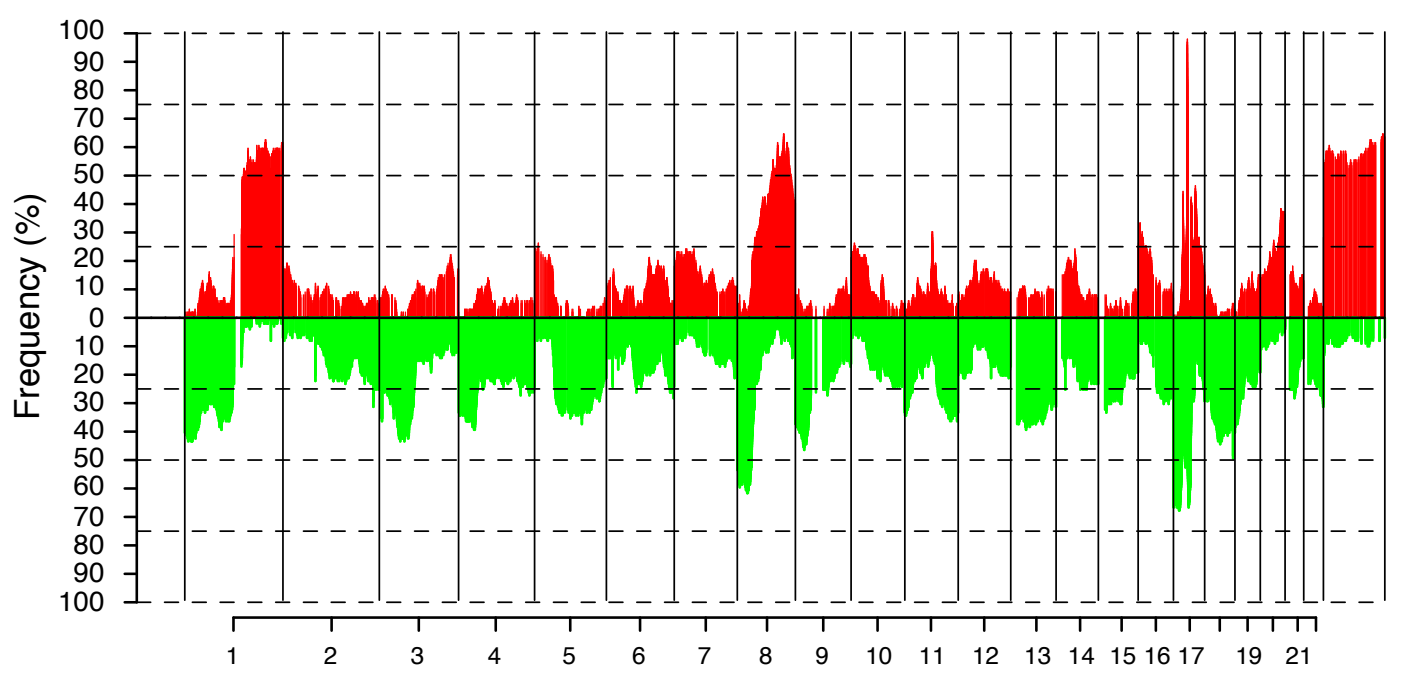

Figure 1 Pattern of CNAs in HER2-amplified breast cancer. (A) Frequency of copy number gain (red) and loss (green) across 218 HER2amplified tumors using log2ratio \pm 0.12 as thresholds for $C N$ gain and loss respectively. Blue regions indicate significant CNAs identified by GISTIC analysis. (B) Frequency of copy number gain (red) and loss (green) across 99 HER2-amplified tumors analyzed by SNP microarrays. Copy number gain and loss were called relative to the GAP-ploidy as described [10].

\section{Pattern of allelic imbalance in HER2-amplified breast cancer}

The pattern of LOH and CNN-AI in HER2-amplified BC were delineated through GAP analysis of 99 cases analyzed by SNP arrays similarly as described [10]. As expected, $\mathrm{LOH}$ was most frequent in regions commonly affected by $\mathrm{CN}$ loss, for example, 8p, 17p, 9p, $18 \mathrm{q}$ and $13 \mathrm{q}$ (Figures $2 \mathrm{~A}$ and $1 \mathrm{~B}$ ). Interestingly, the frequency of CNN-AI was more evenly distributed across chromosomes and seldom exceeded 20\%. The highest CNN-AI frequency in HER2-amplified tumors was observed in a region on $11 \mathrm{q}$ close to the centromere (approximately 30\% CNN-AI) (Figure 2B). The combination of $\mathrm{CNN}-\mathrm{AI}$ and $\mathrm{CN}$ loss calls derived from GAP analysis (Figure 1B) for the 99 tumors revealed that genomic alterations involving loss of at least one allele were highly frequent (> 60\% of cases) in genomic regions on 17p, 8p, and 17q21.3-q22 (Figure $2 \mathrm{C}$ ). Stratification of the 99 cases into six clinicopathological subgroups showed that the fraction of the genome affected by LOH and CNN-AI were less frequent in HER2-amplified ER-positive tumors compared to ER-negative tumors $(P=0.1$ and 0.05 respectively, Wilcoxon's test) (Figure 2D, E). 


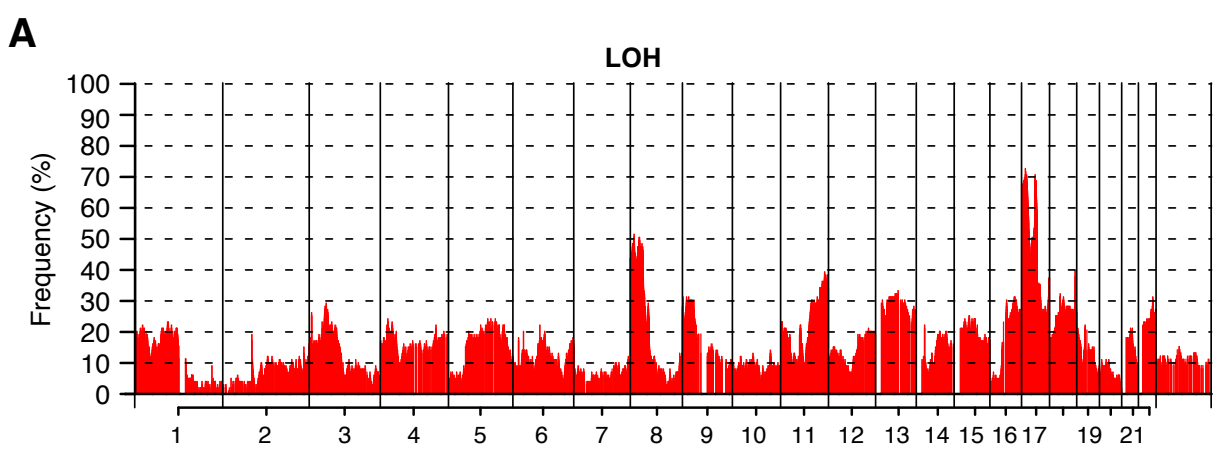

B

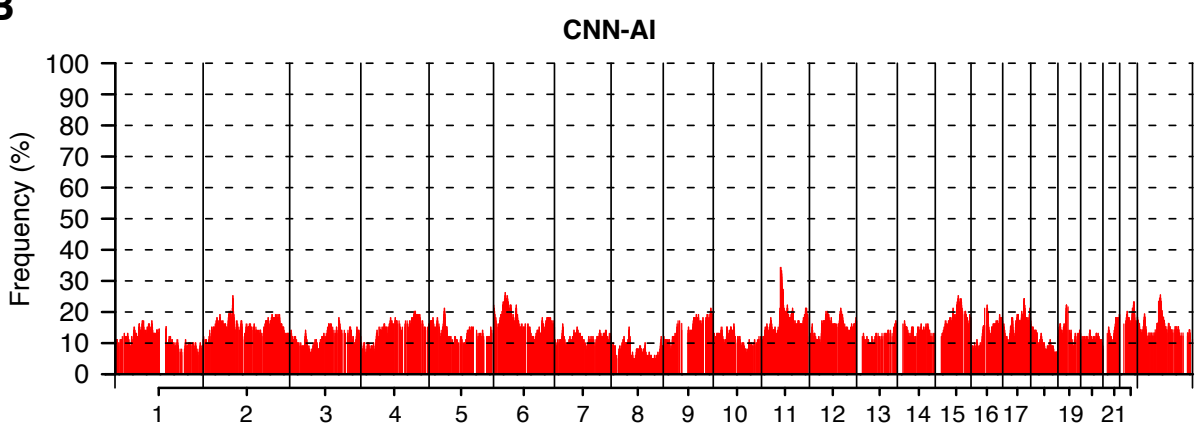

C

CN loss and CNN-AI

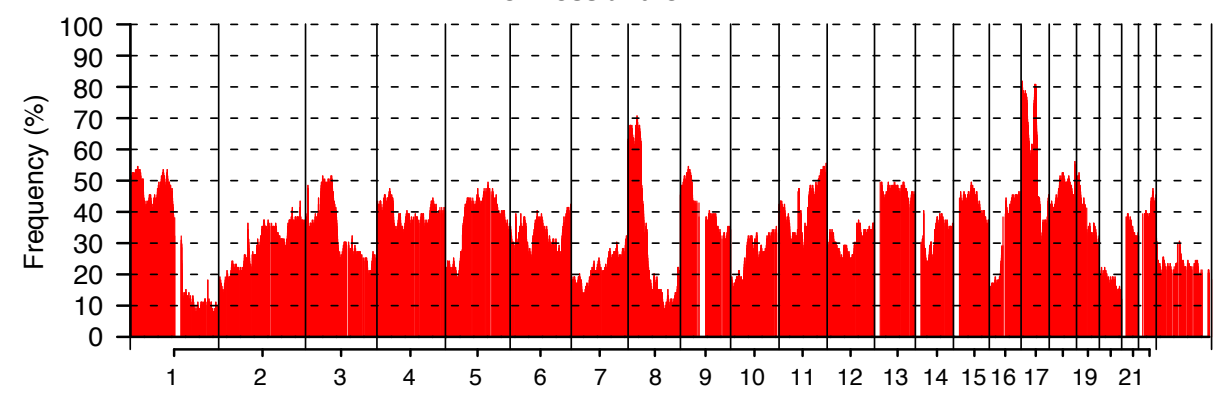

D

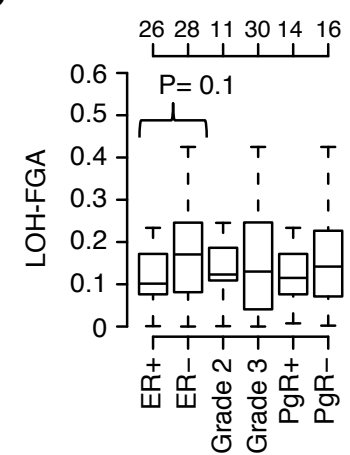

E

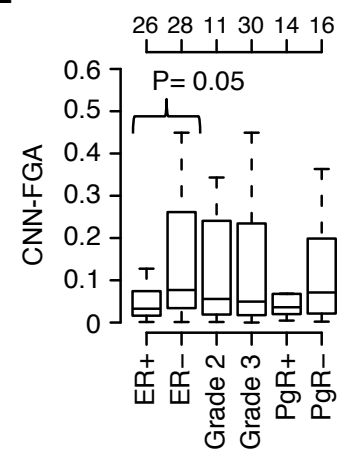

$\mathbf{F}$

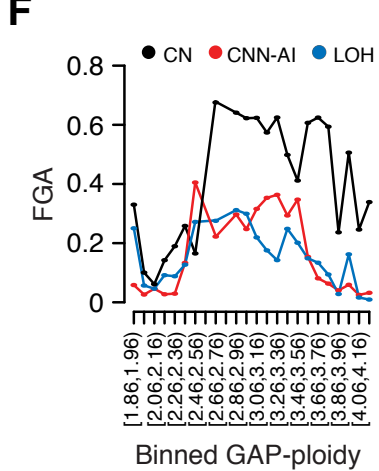

Figure 2 Frequency of LOH and CNN-AI in HER2-amplified breast cancer. (A) Frequency of LOH across the genome for 99 HER2-amplified cases analyzed by SNP arrays. (B) Frequency of CNN-Al across the genome for the 99 cases. (C) Frequency of combined CN loss and CNN-Al across the genome for the 99 cases, where CN loss calls were obtained from GAP analysis. (D) Fraction of the genome affected by LOH for HER2-amplified cases stratified by different clinicopathological variables. Top-axis indicates number of samples in each group. (E) Fraction of the genome affected by CNN-Al for HER2-amplified cases stratified by different clinicopathological variables. Top-axis indicates number of samples in each group. (F) Variation of FGA values versus GAP-ploidy $(n=99)$ for CN (black), CNN-Al (red) and LOH (blue). GAP-ploidy estimates were binned in bins of size 0.1 represented by tick marks on the $x$-axis, and labels for every second bin. For each bin the mean FGA value of included samples are plotted (points) for CN, LOH and CNN-Al. Bins contain different number of samples. P-values were calculated using Wilcoxon's test for indicated groups. 
DNA aneuploid HER2-amplified BC has been associated with higher CN-FGA fractions and worse outcome [5]. However, whether such tumors also harbor more $\mathrm{LOH}$ or CNN-AI events compared to DNA diploid cases or tumors with low CN-FGA have not been fully elucidated. Among the 99 HER2-amplified tumors we found that cases with lower GAP-ploidy (estimated to be diploid or near diploid), with the exception of hypodiploid cases, harbored less $\mathrm{LOH}$ and $\mathrm{CNN}$-AI events, as well as less CNAs compared to cases with higher GAP-ploidy (Figure 2F).

\section{Pattern of allelic imbalance in HER2-amplified compared to HER2-negative breast cancer}

The heterogeneous nature of $\mathrm{BC}$ stresses the importance of proper tumor stratification for evaluation of differences between subgroups of $\mathrm{BC}$. To compare the pattern of $\mathrm{LOH}$ and CNN-AI in HER2-amplified tumors to other $\mathrm{BC}$ subgroups, we performed a similar GAP analysis for the HER2-negative SNP microarray reference data set stratified by PAM50 subtypes (Additional files 1 and 7). Joint analysis of HER2-amplified and HER2-negative cases revealed significant differences between subgroups (Figure 3). Basal-like tumors displayed the highest FGA values for $\mathrm{LOH}$ and $\mathrm{CNN}-\mathrm{AI}$, followed by luminal $\mathrm{B}$ and HER2-amplified/HER2-enriched cases, while luminal A cases displayed the lowest values (Figure 3). Notably, there were no significant differences in LOH-FGA and CNN-FGA values between HER2-enriched tumors stratified by ER-status $(P=0.22$ and 0.39 respectively, Wilcoxon's test, Figure 3$)$. With the exception for hypodiploid cases (GAP-ploidy clearly < 2), HER2-negative tumors showed increasing fractions of $\mathrm{LOH}, \mathrm{CNN}-\mathrm{AI}$ and CNAs with increasing GAP-ploidy similar to HER2-amplified cases (Additional file 8).

\section{DNA ploidy and fraction of aberrant tumor cells in HER2-} amplified compared to HER2-negative breast cancer

To investigate the pattern of DNA ploidy in HER2amplified tumors compared to other subgroups of $\mathrm{BC}$ we first analyzed FCM derived DNA histograms from 338 external cases with connected gene expression and BAC aCGH data (Table S1 in Additional file 1). Stratification of the 338 tumors by PAM50 subtypes revealed differences in the distribution of FCM-ploidy between subtypes. For instance, the luminal A and normal-like subtypes showed the highest proportions of FCM-ploidy values close to $2 \mathrm{~N}$ (most often diploid) (Figure 4A). In contrast, basal-like tumors showed a clear bimodal appearance with peaks at $2 \mathrm{~N}$ and around $2.5 \mathrm{~N}$ (Figure 4A). Furthermore, the HER2-enriched subtype showed a high proportion of cases with FCM-ploidy around $3 \mathrm{~N}$, while luminal B tumors showed pronounced peaks at $2 \mathrm{~N}$ and around $2.6 \mathrm{~N}$ (Figure 4A). Similar patterns were observed when comparing FCM-ploidy from 84 HER2amplified tumors with 150 cases without amplification of HER2 (determined by BAC aCGH) stratified by PAM50 subtypes (Figure 4B). An exception was that the peak at $3 \mathrm{~N}$ was less pronounced in HER2-amplified cases when viewed as a single entity (Figure 4B) compared to HER2-enriched cases (Figure 4A). GAP-ploidy estimates for 407 cases (99 HER2-amplified and 308 HER2-negative with subtype classification) analyzed by SNP arrays showed patterns similar to DNA-FCM results. Again, a bimodal distribution was observed for basal-like tumors, a predominantly diploid pattern for luminal A and normal-like tumors, and a more complex pattern for luminal B and HER2-amplified tumors with peaks at $3 \mathrm{~N}$ and higher (Figure S5A in Additional file 9).

Interestingly, stratification of the $84 \mathrm{FCM}$ analyzed HER2-amplified cases by ER-status revealed differences, in that ER-negative cases displayed a more pronounced bimodal distribution of FCM-ploidy estimates similar to HER2-negative basal-like tumors, while the $3 \mathrm{~N}$ peak was most pronounced in HER2-amplified ER-positive cases (Figure 4C). A similar bimodal distribution of GAPploidy estimates was observed for 28 annotated ERnegative HER2-amplified tumors analyzed by SNP arrays, although with a shift towards $3 \mathrm{~N}$ for the second peak (Figure S5B in Additional file 9). In contrast, the concordance between GAP-ploidy and FCM-ploidy distributions from the two different patient cohorts were poorer for HER2-amplified ER-positive tumors (Figure $4 \mathrm{C}$ and Figure S5B in Additional file 9).

Although quantitative DNA FCM analysis can accurately detect and quantify DNA aneuploid cell populations, it cannot delineate the proportion of, for example, diploid cancer cells versus diploid non-tumor cells. To investigate the fraction of aberrant cells in HER2-amplified and HER2-negative BC stratified by PAM50 subtypes, we compared aberrant cell estimates obtained from GAP analysis for 99 versus 308 cases analyzed by SNP microarrays, respectively. Small differences in aberrant cell estimates between subtypes were observed $(P=$ 0.003 , ANOVA), with the luminal subtypes, generally associated with ER-positivity, showing the highest estimates $(P=0.00004$, Wilcoxon's test, luminal subtypes versus remaining subgroups combined) (Figure 4D). In contrast, no difference in aberrant cell percentages was observed for stratification of all HER2-amplified cases, or HER2-enriched tumors by ER-status ( $P=0.95$ and 0.14 respectively, Wilcoxon's test).

\section{Tumor subclonality in breast cancer revealed by SNP array analysis}

$\mathrm{BC}$ often display extensive intra-tumor heterogeneity regarding, for example, cell size, morphology, proliferation and genomic alterations [39-41]. To a certain extent, 


\section{A}

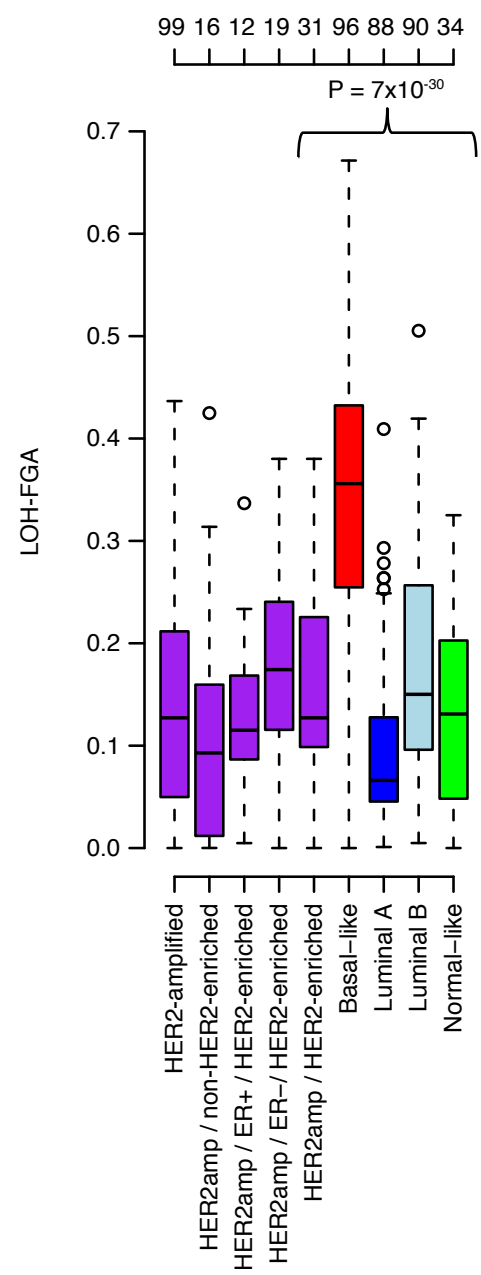

B

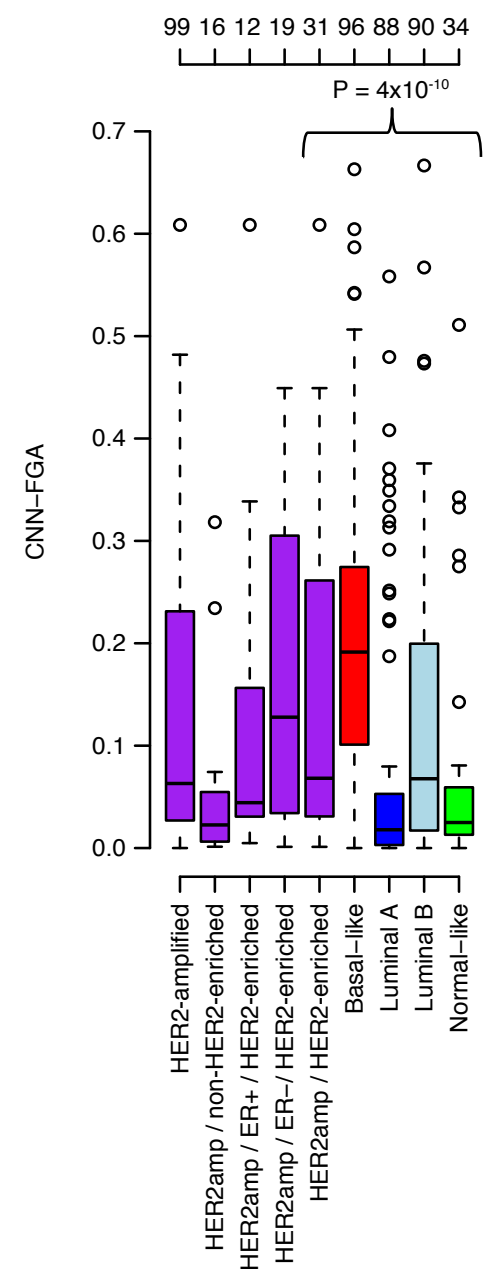

Figure 3 Fraction of LOH and CNN-AI in HER2-amplified and HER2-negative breast cancer. (A) Fraction of the genome affected by LOH for HER2-amplified cases stratified by PAM50 subtype and ER-status compared to HER2-negative cases stratified by PAM50 subtypes. Top-axis indicates number of samples in each group. A significant difference in LOH-FGA is observed between HER2-amplified and HER2-negative cases stratified by PAM50 subtype $\left(P=7 \times 10^{-30}\right.$, ANOVA). A similar difference was observed when comparing LOH-FGA estimates for all HER2amplified tumors against HER2-negative cases stratified by PAM50 subtype ( $P=3 \times 10^{-33}$, ANOVA). (B) Fraction of the genome affected by CNNAl for HER2-amplified cases stratified by PAM50 subtype and ER-status compared to HER2-negative cases stratified by PAM50 subtypes. Top-axis indicates number of samples in each group. A significant difference in CNN-FGA is observed between HER2-amplified and HER2-negative cases stratified by PAM50 subtype $\left(P=4 \times 10^{-10}\right.$, ANOVA). A similar difference was observed when comparing CNN-FGA estimates for all HER2amplified tumors against HER2-negative cases stratified by PAM50 subtype $\left(P=2 \times 10^{-10}\right.$, ANOVA).

aCGH and SNP arrays allow detection of CNAs that differ in prevalence among analyzed cells. To investigate the prevalence of subclonal $\mathrm{CN}$ events in HER2-amplified versus HER2-negative BC, we employed a conservative approach limited to larger $\mathrm{CN}$ deletions only (see Material and methods). In the 99 HER2-amplified BCs analyzed by SNP arrays, this approach identified 39 cases (39\%) with subclonal CN loss. By comparison, in the 308 HER2-negative cases 98 samples (32\%) were identified as having subclonal $\mathrm{CN}$ loss. Differences in the prevalence of subclonal CN loss events were observed between HER2-amplified/
HER2-enriched and HER2-negative cases stratified by molecular subtype ( $P=3 \times 10^{-6}$, Chi-square test). HER2amplified/HER2-enriched cases together with basal-like tumors showed the highest prevalence of subclonal $\mathrm{CN}$ loss, followed by luminal B tumors, while luminal A and normal-like tumors displayed the lowest fractions (Figure 5). Subclonal $\mathrm{CN}$ loss was associated with higher fractions of LOH, CNN-AI, CNAs and higher GAP-ploidy for HER2-amplified, HER2-amplified/HER2-enriched, luminal A and luminal B cases $(P<0.05$, Wilcoxon's tests). For basal-like tumors subclonal $\mathrm{CN}$ loss was significantly 
A

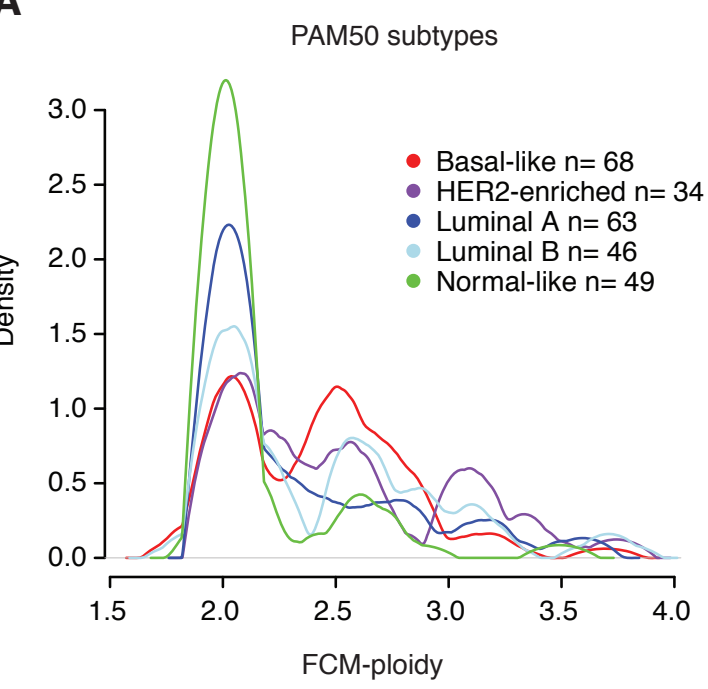

C

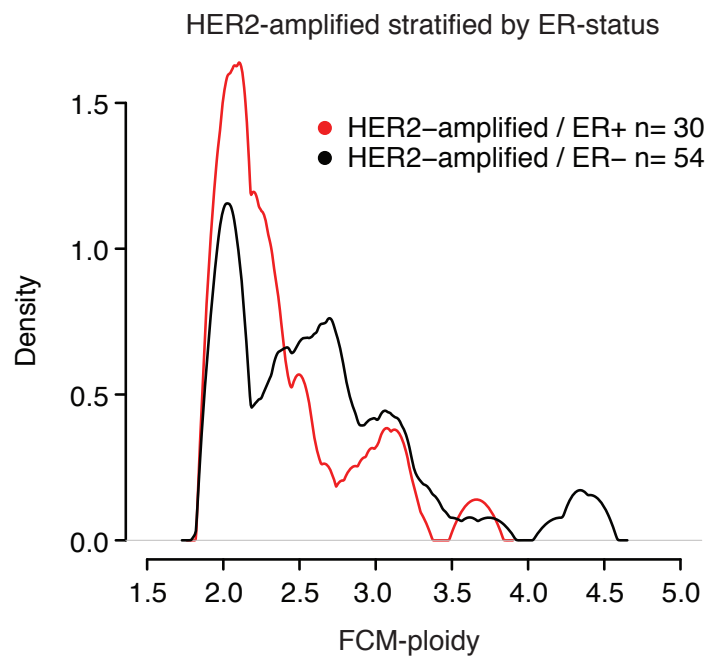

B

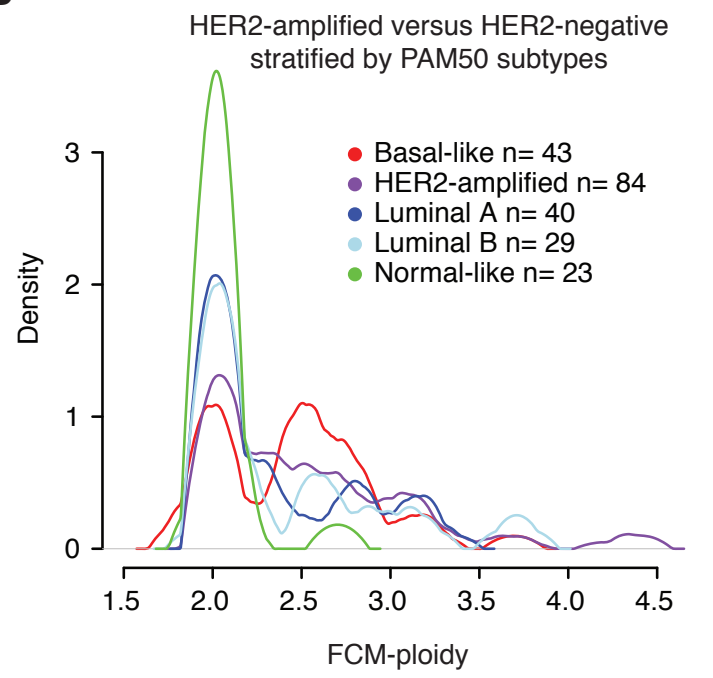

D

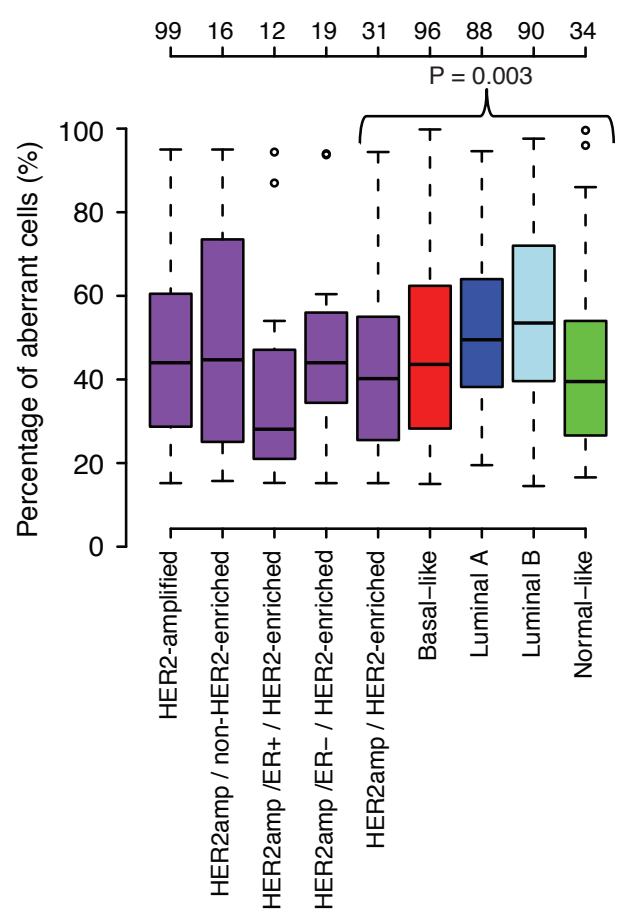

Figure 4 Tumor ploidy and percentage of aberrant tumor cells in HER2-amplified compared to HER2-negative breast cancer. (A) Distribution of FCM-ploidy across PAM50 subtypes for 260 cases with concurrent gene expression data. Of the 34 HER2-enriched cases, 21 had concurrent BAC aCGH data. 19 of these 21 cases showed amplification of HER2 by BAC aCGH, (B) Distribution of FCM-ploidy across 219 breast cancer samples grouped as HER2-amplified by BAC aCGH, or HER2-negative by BAC aCGH and further stratified by PAM50 subtype. (C) Distribution of FCM-ploidy for 84 HER2-amplified cases stratified by ER-status. (D) Distribution of percentage of aberrant cells estimated by GAP analysis of 407 breast cancers across HER2-amplified tumors and HER2-negative tumors stratified by PAM50 subtypes and ER-status. A significant difference in aberrant cell estimates is observed between HER2-amplified and HER2-negative cases stratified by PAM50 subtype $(P=0.003$, ANOVA). A similar difference was observed when comparing aberrant cell estimates for all HER2-amplified tumors against HER2-negative cases stratified by PAM50 subtype ( $P=0.02$, ANOVA). In A to C, curves were generated by an Epanechnikov smoothing kernel with 0.08 smoothing bandwidth. 


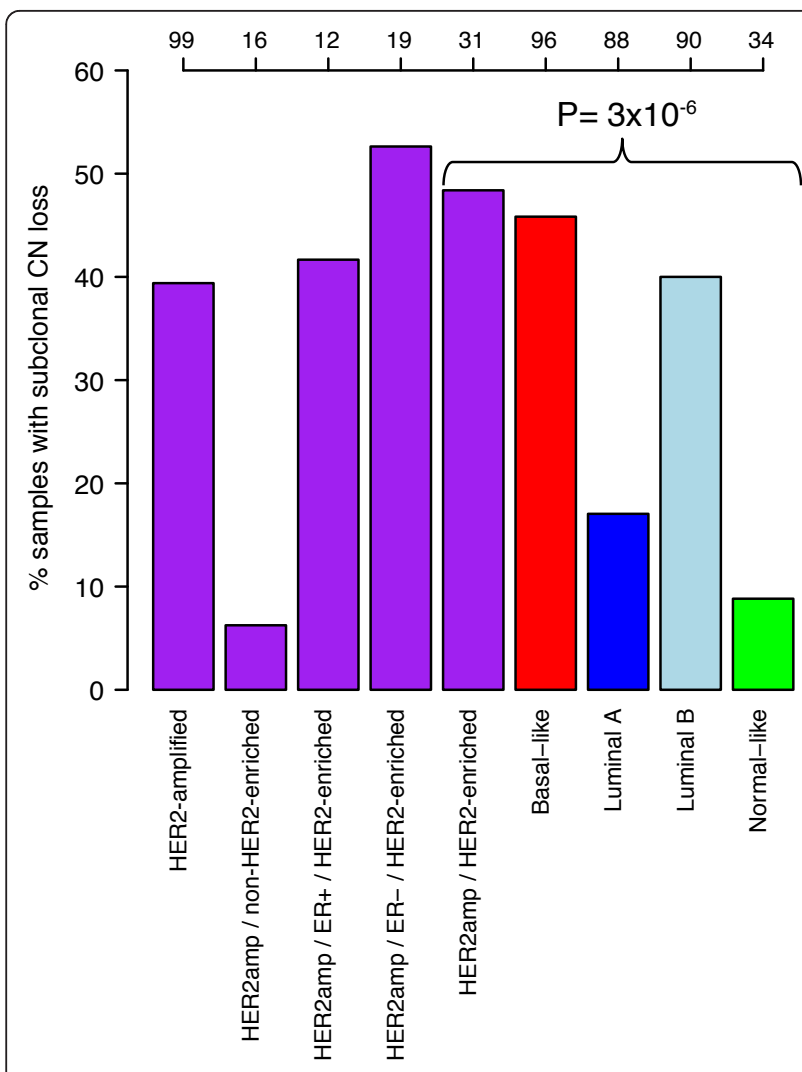

Figure 5 Prevalence of subclonal $\mathrm{CN}$ loss in breast cancer. Prevalence of subclonal CN loss was estimated in 99 HER2-amplified cases and 308 HER2-negative cases with PAM50 subtype classification analyzed by SNP arrays revealing differences in the frequency of subclonal CN loss events between subgroups. Top-axis indicates total number of cases for each bar. P-value was calculated using the Chi-square test for indicated groups.

associated with higher CN-FGA fractions and higher GAP-ploidy $(P<0.0001$, Wilcoxon's test), while only weakly associated with higher LOH-FGA fractions $(P=$ 0.11 , Wilcoxon's test).

\section{High-level amplification events appear as monoallelic in HER2-amplified breast cancer}

Genes residing in regions subjected to genomic amplification are oncogene candidates and gene amplification may occur through different mechanisms. SNP arrays offer the possibility to dissect the gene amplification process on an allele specific level as demonstrated by LaFramboise et al. [42]. In a panel of lung cancer tumors and cell lines essentially all amplification events appeared to be monoallelic; that is, gene amplification exclusively involved only one of the two parental chromosomes [42]. To investigate whether this observation stands true also in HER2-amplified BC, we aimed to identify more focal high-level amplification events in the Illumina Lund-HER2-SNP set by selecting only smaller segments (>50 kbp) with a high partitioned CN log2ratio (> 0.7). These criteria identified 108 segments among the 26 cases. Integration of partitioned $\mathrm{CN}$ and $\mathrm{mBAF}$ values [12] for these 108 segments showed that the absolute majority of them displayed simultaneously high $\mathrm{CN}$ and $\mathrm{mBAF}$ values (Figure 6A). These results suggest that high-level amplifications involve only one of the parental chromosomes also in HER2-amplified BC.

In contrast to the less frequent and more focal highlevel amplifications, amplifications involving a larger part of a chromosome arm but with a lower number of additional gene copies are more frequent in $\mathrm{BC}$. To investigate whether such amplification events also preferentially target one parental chromosome, we identified 90 cases from the 99 HER2-amplified tumors analyzed by SNP arrays that harbored 835 genomic regions $>2 \mathrm{Mbp}$ and with a total $\mathrm{CN}>3$ compared to the estimated GAP-ploidy for respective sample. Similar to high-level amplifications, the majority of identified events displayed amplification of predominantly one of the two parental chromosomes (Figure 6B).

\section{Discussion}

HER2 + BC represents an important clinical subgroup of the disease due to availability of effective targeted therapy both in the adjuvant and metastatic setting. Clinically, the subgroup is defined by HER2 gene amplification and/or protein overexpression; however, genome-wide molecular analyses have shown that $\mathrm{BC}$ with genomic amplification of HER2 (HER2-amplified $\mathrm{BC}$ ) is heterogeneous with regards to gene expression patterns, CNAs and outcome $[4,5,20]$. Thus, further characterization of HER2-amplified tumors at the gene level may have implications for improved diagnosis, prognosis and prediction.

Here we report the first integrated analysis of CNAs and $\mathrm{AI}$ in a large cohort of HER2-amplified BC profiled by high-density genomic microarrays, allowing a comprehensive description of the genomic landscape of CNAs, amplifications, $\mathrm{LOH}$ and CNN-AI. When comparing results to our previous study of 200 HER2-amplified tumors profiled by BAC aCGH [5], we corroborated several previous findings regarding, for example, amplifications, and found a striking similarity in the overall pattern of $\mathrm{CN}$ gain and loss. By comparing significant CNAs identified by GISTIC analysis in the current and former study [5], we were able to define a core set of genomic regions commonly affected by $\mathrm{CN}$ gain and loss in HER2-amplified BC across different genomic microarray platforms that may serve as a list of potential targets for further studies (Additional file 4). Differences between the two studies may be explained by usage of different array platforms, data analysis methods and cohort composition. Importantly, however, the 


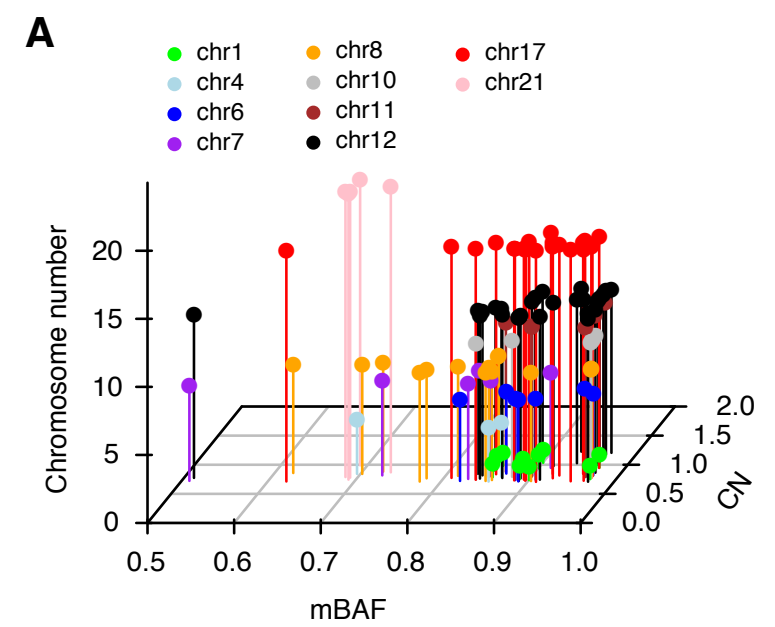

B

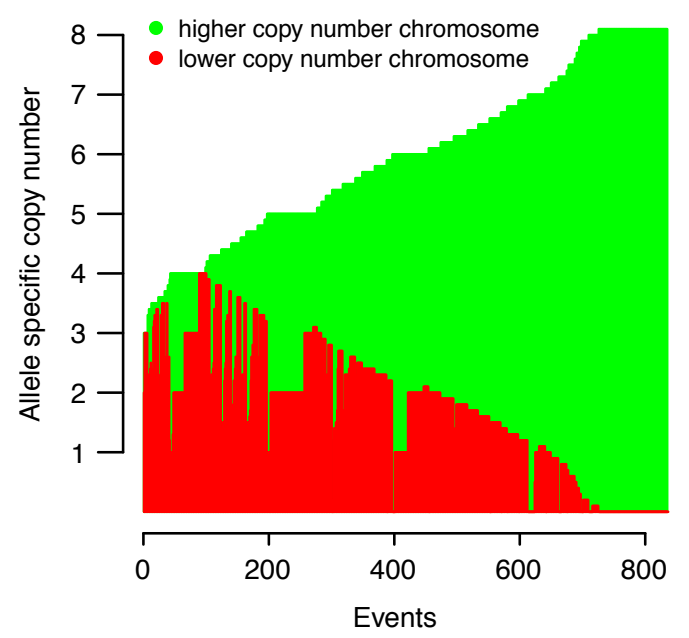

Figure 6 Monoallelic amplification in HER2-amplified breast cancer. (A) High-level amplifications predominantly show amplification of one parental chromosome in HER2-amplified breast cancer. Partitioned mBAF [12] estimates are plotted against corresponding partitioned $\mathrm{CN}$ values for 108 genomic segments > $50 \mathrm{kbp}$ in size and with a partitioned log2ratio $>0.7$ from cases in the Lund-HER2-SNP set, representing high-level amplification segments in this data set. The color and height of segments on the $z$-axis indicate chromosome location. BAF estimates range between 0 and 1 reflecting the proportion of the two parental chromosomes for a given SNP. Due to the symmetry of BAF profiles for current genome-wide SNP arrays, BAF profiles may be reflected along the central 0.5 axis into mBAF estimates [12]. In a normal sample mBAF values close to 0.5 represent a heterozygous state (AB) for a given SNP, whereas values close to 1 represent a homozygous state (AA or BB). In tumor samples allelic imbalances are seen as a deviation of heterozygous SNPs from 0.5. The amplitude of the deviation is a function of the type of aberration, fraction of aberrant cells carrying the aberration and tumor ploidy. Thus, for amplification events in tumor samples higher mBAF values indicate additional copies of one of the two parental chromosomes in the amplified region. (B) Distribution of estimated allele specific copy numbers from GAP analysis for 835 events in 90 of 99 samples analyzed by SNP arrays, $>2 \mathrm{Mbp}$ in size and with a total CN $>3$ compared to the GAP- ploidy for respective sample. The latter means that if the GAP-ploidy of a sample is 2.58 an event must have a total $C N>5.58$ to be included. For each event on the $x$-axis allele specific copy numbers for the two parental chromosomes are shown as green and red bars. The total CN is the sum of the height of the red and green bars, and is truncated at eight by GAP. GAP returns allele specific copy numbers as numerical values, for example, 2.5, for possible identification of sub-clonal events, thus the steps in the plot are not discrete.

concordance between our two studies emphasizes that evaluation of CNAs in a heterogeneous subgroup such as HER2-amplified BC needs to be performed in large sample sets in order to pinpoint recurrent alterations.

Genome-wide analyses of $\mathrm{LOH}, \mathrm{CNN}-\mathrm{AI}$, tumor ploidy, fraction of aberrant cells and subclonal $\mathrm{CN}$ events utilizing genomic microarrays have been scarce in $\mathrm{BC}$ due to the often high sample complexity, lack of appropriate analysis methods and low sample numbers. In the current study, we applied GAP [13] to SNP array data in combination with conventional DNA-FCM to analyze genomic alterations on an allele specific level, patterns of tumor ploidy, tumor subclonality and fraction of aberrant cells in a large set HER2-amplified and HER2-negative tumors stratified by molecular subtype. In HER2-amplified cases as well as HER2-negative subgroups the pattern of $\mathrm{LOH}$ was, as could be expected from the $\mathrm{LOH}$ definition, strongly associated with the pattern of $\mathrm{CN}$ loss (Figures 1 and 2, Additional file 7). In contrast, $\mathrm{CNN}$ - AI events were more evenly distributed across chromosomes in HER2-amplified tumors, seldom exceeding $>20 \%$ in frequency and not targeting specific genomic regions (Figure 2). Interestingly, a similar low and evenly distributed CNN-AI pattern was also observed in HER2-negative luminal A, luminal B and normal-like tumors (Additional file 7). In contrast, basal-like tumors showed slightly higher frequencies potentially explained by a higher frequency of triploid cases $(3 \mathrm{~N})$. This suggests that CNN-AI appears as a less frequent genome-wide additive event in the majority of breast cancers. Moreover, in relation to other BC subtypes the patterns of $\mathrm{LOH}$ and CNN-AI were similar to findings by Van Loo et al. [10], and also mimicked the general pattern of CN-FGA reported for $\mathrm{BC}$ gene expression subtypes $[5,36]$. However, based on our joint analysis of 407 HER2-amplified and HER2-negative cases, we were not able to corroborate previously reported subtype specific pattern of aberrant cell estimates [10] (Figure 4D). This discrepancy between studies warrants further investigation, but indicates that these types of estimations may be difficult to systematically reproduce. Interestingly, the finding in the current study that HER2-amplified and predominantly ER- 
negative basal-like tumors show lower aberrant cell estimates is consistent with observations of considerable lymfocytic infiltration in these subtypes [43-45]. In agreement with observations in lung cancer [42] we found that amplifications in HER2-amplified BC were essentially monoallelic, as amplification preferentially targeted one of the two parental chromosomes (Figure 6). This form of amplification may be a mechanism for targeting activating oncogene mutations and has previously been observed on an individual gene level $[46,47]$. The full significance of this putative mechanism, however, remains to be investigated in more detail using, for example, rapidly evolving sequencing techniques.

Aneuploidization is one of the most common properties of cancer and has generally been associated with worse prognosis and more advanced disease [48]. In support of an overall higher genomic complexity for aneuploid $\mathrm{BC}$, we found that increasing GAP-ploidy was associated with higher fractions of $\mathrm{LOH}, \mathrm{CNN}-\mathrm{AI}$ and CNAs, as well as higher occurrence of subclonal $\mathrm{CN}$ loss events irrespective of $\mathrm{BC}$ subtype (Figure $2 \mathrm{~F}$ and Additional file 8). Not surprisingly, the patterns of DNA ploidy, subclonal $\mathrm{CN}$ events, fractions of $\mathrm{LOH}, \mathrm{CNAs}$ and CNN-AI across HER2-amplified and HER2-negative tumors appear consistent with the overall prognosis for the subgroups. For instance, luminal A and normal-like tumors, which generally display the best outcome, are more frequently diploid and less complex. In contrast, basal-like, HER2-amplified and luminal B cases display more complex patterns in line with their poorer outcome and often higher stage [24,36]. Although both GAP and a similar method termed Allele-Specific Copy number Analysis of Tumors [10] allow estimation of in silico tumor ploidy from SNP array data, both methods have difficulties in analyzing certain types of samples $[10,13]$. To get a more unbiased analysis of the pattern of DNA ploidy across BC subtypes, we used quantitative DNA FCM data for 338 unrelated BCs also analyzed by gene expression microarrays and $\mathrm{BAC}$ aCGH. Using this large sample set we were able to corroborate several findings by Van Loo et al. [10], as well as results from our GAP analysis, for example, showing that the molecular BC subtypes display different patterns of tumor DNA ploidy. Shifts between FCM and GAP-ploidy peak positions, exemplified by HER2-negative basal-like tumors (Figures 4A and S5A in Additional file 9), may be explained by that the latter estimation aims to account for normal cell contamination, while the former represents a mere total DNA summarization.

Interestingly, the bimodal distribution of tumor ploidy displayed by HER2-negative basal-like tumors was also observed in ER-negative HER2-amplified tumors, and in ER-negative tumors in general irrespective of subtype (data not shown). These findings imply that the evolutionary hypothesis for basal-like tumors suggested by Van Loo et al. [10], of a reduction from a diploid to a partial haploid state followed by whole-genome duplication, is not limited to a specific molecular subtype but appears to be more general for ER-negative BC. This apparently more general difference in DNA ploidy patterns between ER-positive and negative $\mathrm{BC}$ most likely explain differences in $\mathrm{LOH}$ and CNN-AI fractions observed between subgroups/subtypes of HER2-amplified $\mathrm{BC}$ as, for example, ER-negative tumors are overrepresented in the HER2-enriched subtype. The HER2enriched subtype has been found to often comprise the majority of HER2-amplified cases in gene expression studies. However, based on findings from several recent studies, including the current one, it appears clear that 1) the HER2-enriched subtype identified by different single sample predictors is not synonymous with the clinically defined HER 2 + subgroup, 2) the subtype includes a notable fraction of HER2-amplified ER-positive cases, 3) HER2-amplified cases are found in all gene expression subtypes at varying frequencies, and 4) HER2-negative cases are found in the HER2-enriched subtype $[5,20,24,25]$. As an example of the latter, we found that $7.5 \%$ of samples in the 346-sample HER2negative SNP reference set were classified as HER2enriched by the PAM50 single sample predictor.

In summary, the comprehensive analysis presented herein confirms and extends several findings about the reported molecular subtypes of $\mathrm{BC}$, but also emphasizes the strong association of different types of genomic aberrations with tumor DNA aneuploidy, irrespective of subtype. The molecular $\mathrm{BC}$ subtypes have repeatedly been shown to display different CNAs $[36,49,50]$, and, lately, also differences in fractions of $\mathrm{LOH}$ and $\mathrm{CNN}-\mathrm{AI}$ [10]. We demonstrate that tumors harboring few CNAs typically also display less $\mathrm{LOH}$, less CNN-AI, lower tumor ploidy and less frequent occurrence of subclonal events, pointing towards an overall lower complexity irrespective of subtype.

\section{Conclusions}

We have conducted a comprehensive survey of genomic alterations in the largest cohort of HER2-amplified breast cancer cases profiled by aCGH and SNP arrays reported to date. Taken together, the results presented here provide a comprehensive view of the landscape of genomic alterations including CNAs, $\mathrm{LOH}, \mathrm{CNN}-\mathrm{AI}$ and tumor DNA ploidy occurring in HER2-amplified tumors in context of other BC subgroups. Furthermore, our results emphasize that analysis of genomic alterations in heterogeneous subgroups, such as HER2-amplified $\mathrm{BC}$, need large sample numbers in order to draw more definite conclusions. 


\section{Additional material}

Additional file 1: Identification of HER2-amplified cases and patient and tumor characteristics for reference data sets. A pdf file containing figure S1 showing HER2 CN estimates for identified HER2amplified cases from public repositories, and a table (S1) of patient and tumor characteristics for HER2-amplified, HER2-negative tumors in the SNP reference breast cancer data set, and the 338 tumors analyzed by FCM.

Additional file 2: Supplementary Methods. A Word document containing supplementary information about used methods and data processing.

Additional file 3: Significant GISTIC regions identified from analysis of 218 HER2-amplified breast cancers. An Excel table presenting significant GISTIC regions and frequency of amplification in these regions, as well as sample identifiers for the 218 primary tumors used for GISTIC analysis.

Additional file 4: Recurrent GISTIC regions in HER2-amplified breast cancer. An Excel table presenting GISTIC regions that overlaps with a previous study of 200 HER2-amplified cases analyzed by BAC aCGH.

Additional file 5: CNAs in HER2-amplified breast tumors and cell lines. A pdf file containing six figures, S2A-F, showing the overlap of GISTIC regions identified in the current and a former BAC aCGH study, pattern of CNAs in 16 HER2-amplified breast cancer cell lines, shortest region of amplification including the HER2 gene, HER2-amplified cases defining the centromeric and telomeric breakpoints for the shortest region of amplification analysis, and GISTIC regions stratifying HER2amplified breast cancer based on ER-status, respectively.

Additional file 6: Recurrent amplifications in HER2-amplified breast cancer. An Excel table describing recurrent amplifications in the 218 HER2-amplified cases, and the integration with concomitant gene expression data for genes in amplified regions. Additionally, the overlap between recurrent amplifications with a previous study of 200 HER2amplified cases analyzed by BAC aCGH is presented.

Additional file 7: Frequency of LOH and CNN-AI in HER2-negative breast cancers analyzed by GAP and stratified by PAM50 subtypes. A pdf file containing four figures, S3A-D showing frequency of $\mathrm{LOH}$ (upper panel) and CNN-Al (lower panel) for HER2-negative tumors classified as basal-like, luminal A, luminal B, and normal-like using PAM50.

Additional file 8: Variation of FGA values versus GAP-ploidy for HER2-amplified and HER2-negative breast cancers. A pdf file containing five figures, S4A-E, showing the pattern of LOH-FGA, CNNFGA and CN-FGA for HER2-amplified cases, HER2-negative basal-like tumors, HER2-negative luminal A tumors, HER2-negative luminal B tumors and HER2-negative normal-like tumors respectively.

Additional file 9: Tumor ploidy for HER2-amplified cases estimated by GAP analysis. A pdf file containing two figures, S5A-B, showing the distribution of GAP-ploidy estimates for 407 HER2-amplified and HER2negative cases stratified according to subtype, and HER2-amplified cases stratified by ER-status respectively.

\section{Abbreviations}

aCGH: array-based Comparative Genomic Hybridization; Al: allelic imbalance; BAF: B allele frequency; BC: breast cancer; CN: copy number; CNN-Al: copy number neutral allelic imbalance; CNA: copy number alteration; ER: estrogen receptor; FCM: flow cytometry; FGA: fraction of the genome altered; GAP: genome alteration print; GISTIC: genomic identification of significant targets in cancer; HER2: Human epidermal growth factor receptor 2; LOH: loss of heterozygosity; SNP: single nucleotide polymorphism

\section{Acknowledgements}

The authors wish to acknowledge Anna Karlsson, Jeanette Valcich and Susanne Jonsson at the SCIBLU Genomics Core Facility at Lund University for technical support with Illumina SNP analyses. Financial support for this study was provided by the Swedish Cancer Society, the Knut and Alice Wallenberg Foundation, the Foundation for Strategic Research through the
Lund Centre for Translational Cancer Research (CREATE Health), the Mrs. Berta Kamprad Foundation, the Gunnar Nilsson Cancer Foundation, the Swedish Research Council, the Lund University Hospital Research Funds, the Gustav V:s Jubilee Foundation, the IngaBritt and Arne Lundberg Foundation, and a donation in memory of Marianne Nygren. The SCIBLU Genomics center is supported by governmental funding of clinical research within the national health services (ALF) and by Lund University.

\section{Author details}

'Department of Oncology, Clinical Sciences, Lund University and Skåne University Hospital, Barngatan 2B, SE 22185 Lund, Sweden. ${ }^{2}$ CREATE Health Strategic Center for Translational Cancer Research, Lund University, BMC C13, SE 22184, Lund, Sweden. ${ }^{3}$ Lund Strategic Research Center for Stem Cell Biology and Cell Therapy, Klinikgatan 26, Biomedical Center, Lund University, SE-22184 Lund, Sweden.

\section{Authors' contributions}

JS conceived of the study and performed microarray data analysis with support by GJ and MR. BB performed FCM analysis. JS wrote the manuscript with the assistance of GJ, MR, BB and $\AA$ B. All authors read and approved the final manuscript

\section{Competing interests}

JS and $\AA \mathrm{B}$ have received honoraria from Roche. The other authors declare that they have no competing interests.

Received: 26 May 2011 Revised: 21 November 2011

Accepted: 14 December 2011 Published: 14 December 2011

\section{References}

1. Slamon DJ, Clark GM, Wong SG, Levin WJ, Ullrich A, McGuire WL: Human breast cancer: correlation of relapse and survival with amplification of the HER-2/neu oncogene. Science 1987, 235:177-182.

2. Wolff AC, Hammond ME, Schwartz JN, Hagerty KL, Allred DC, Cote RJ, Dowsett M, Fitzgibbons PL, Hanna WM, Langer A, McShane LM, Paik S, Pegram MD, Perez EA, Press MF, Rhodes A, Sturgeon C, Taube SE, Tubbs R, Vance $\mathrm{GH}$, van de Vijver M, Wheeler TM, Hayes DF: American Society of Clinical Oncology/College of American Pathologists guideline recommendations for human epidermal growth factor receptor 2 testing in breast cancer. J Clin Oncol 2007, 25:118-145.

3. Paik S, Hazan R, Fisher ER, Sass RE, Fisher B, Redmond C, Schlessinger J, Lippman ME, King CR: Pathologic findings from the National Surgical Adjuvant Breast and Bowel Project: prognostic significance of erbB-2 protein overexpression in primary breast cancer. J Clin Oncol 1990, 8:103-112.

4. Staaf J, Ringner M, Vallon-Christersson J, Jonsson G, Bendahl PO, Holm K, Arason A, Gunnarsson H, Hegardt C, Agnarsson BA, Luts L, Grabau D, Ferno M, Malmstrom PO, Johannsson OT, Loman N, Barkardottir RB, Borg A: Identification of subtypes in human epidermal growth factor receptor 2-positive breast cancer reveals a gene signature prognostic of outcome. J Clin Oncol 2010, 28:1813-1820.

5. Staaf J, Jönsson G, Ringner M, Vallon-Christersson J, Grabau D, Arason A, Gunnarsson H, Agnarsson B, Malmström P, Johannsson O, Loman N, Barkardottir R, Borg $\AA$ : High-resolution genomic and expression analyses of copy number alterations in HER2-amplified breast cancer. Breast Cancer Res 2010, 12:R25.

6. Marchio C, Natrajan R, Shiu K, Lambros M, Rodriguez-Pinilla S, Tan D, Lord C, Hungermann D, Fenwick K, Tamber N, Mackay A, Palacios J, Sapino A, Buerger $\mathrm{H}$, Ashworth A, Reis-Filho J: The genomic profile of HER2-amplified breast cancers: the influence of ER status. J Patho/ 2008, 216:399-407.

7. Arriola E, Marchio C, Tan DS, Drury SC, Lambros MB, Natrajan R, RodriguezPinilla SM, Mackay A, Tamber N, Fenwick K, Jones C, Dowsett M, Ashworth A, Reis-Filho JS: Genomic analysis of the HER2/TOP2A amplicon in breast cancer and breast cancer cell lines. Lab Invest 2008, 88:491-503.

8. Haverty PM, Fridlyand J, Li L, Getz G, Beroukhim R, Lohr S, Wu TD, Cavet G, Zhang Z, Chant J: High-resolution genomic and expression analyses of copy number alterations in breast tumors. Genes Chromosomes Cancer 2008, 47:530-542.

9. Kadota M, Sato M, Duncan B, Ooshima A, Yang HH, Diaz-Meyer N, Gere S, Kageyama S, Fukuoka J, Nagata T, Tsukada K, Dunn BK, Wakefield LM, 
Lee MP: Identification of novel gene amplifications in breast cancer and coexistence of gene amplification with an activating mutation of PIK3CA. Cancer Res 2009, 69:7357-7365.

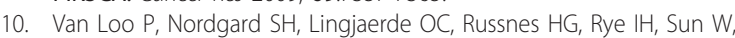
Weigman VJ, Marynen P, Zetterberg A, Naume B, Perou CM, BorresenDale AL, Kristensen VN: Allele-specific copy number analysis of tumors. Proc Natl Acad Sci USA 2010, 107:16910-16915.

11. Zhang Y, Martens JW, Yu JX, Jiang J, Sieuwerts AM, Smid M, Klijn JG, Wang $Y$, Foekens JA: Copy number alterations that predict metastatic capability of human breast cancer. Cancer Res 2009, 69:3795-3801.

12. Staaf J, Lindgren D, Vallon-Christersson J, Isaksson A, Goransson H, Juliusson G, Rosenquist R, Hoglund M, Borg A, Ringner M: Segmentationbased detection of allelic imbalance and loss-of-heterozygosity in cancer cells using whole genome SNP arrays. Genome Biol 2008, 9:R136.

13. Popova T, Manie E, Stoppa-Lyonnet D, Rigaill G, Barillot E, Stern MH: Genome Alteration Print (GAP): a tool to visualize and mine complex cancer genomic profiles obtained by SNP arrays. Genome Biol 2009, 10: R128.

14. Sun W, Wright FA, Tang Z, Nordgard SH, Van Loo P, Yu T, Kristensen VN, Perou CM: Integrated study of copy number states and genotype calls using high-density SNP arrays. Nucleic Acids Res 2009, 37:5365-5377.

15. SCIBLU Genomics. [http://www.lth.se/sciblu].

16. Nikolsky Y, Sviridov E, Yao J, Dosymbekov D, Ustyansky V, Kaznacheev V, Dezso Z, Mulvey L, Macconaill LE, Winckler W, Serebryiskaya T, Nikolskaya T, Polyak K: Genome-wide functional synergy between amplified and mutated genes in human breast cancer. Cancer Res 2008, 68:9532-9540.

17. Beroukhim R, Mermel CH, Porter D, Wei G, Raychaudhuri S, Donovan J, Barretina J, Boehm JS, Dobson J, Urashima M, Mc Henry KT, Pinchback RM, Ligon AH, Cho YJ, Haery L, Greulich H, Reich M, Winckler W, Lawrence MS, Weir BA, Tanaka KE, Chiang DY, Bass AJ, Loo A, Hoffman C, Prensner J, Liefeld T, Gao Q, Yecies D, Signoretti S, et al: The landscape of somatic copy-number alteration across human cancers. Nature 2010, 463:899-905.

18. Russnes HG, Vollan HK, Lingjaerde OC, Krasnitz A, Lundin P, Naume B,

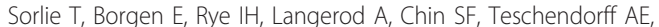
Stephens PJ, Maner S, Schlichting E, Baumbusch LO, Karesen R, Stratton MP, Wigler M, Caldas C, Zetterberg A, Hicks J, Borresen-Dale AL: Genomic architecture characterizes tumor progression paths and fate in breast cancer patients. Sci Transl Med 2010, 2:38ra47.

19. Kan Z, Jaiswal BS, Stinson J, Janakiraman V, Bhatt D, Stern HM, Yue P Haverty PM, Bourgon R, Zheng J, Moorhead M, Chaudhuri S, Tomsho LP, Peters BA, Pujara K, Cordes S, Davis DP, Carlton VE, Yuan W, Li L, Wang W, Eigenbrot C, Kaminker JS, Eberhard DA, Waring P, Schuster SC, Modrusan Z, Zhang Z, Stokoe D, de Sauvage FJ, et al: Diverse somatic mutation patterns and pathway alterations in human cancers. Nature 2010, 466:869-873.

20. Sircoulomb F, Bekhouche I, Finetti P, Adelaide J, Ben Hamida A, Bonansea J, Raynaud S, Innocenti C, Charafe-Jauffret E, Tarpin C, Ben Ayed F, Viens P, Jacquemier J, Bertucci F, Birnbaum D, Chaffanet M: Genome profiling of ERBB2-amplified breast cancers. BMC Cancer 2010, 10:539.

21. Staaf J, Vallon-Christersson J, Lindgren D, Juliusson G, Rosenquist $R$, Hoglund M, Borg A, Ringner M: Normalization of Illumina Infinium wholegenome SNP data improves copy number estimates and allelic intensity ratios. BMC Bioinformatics 2008, 9:409.

22. Hu X, Stern HM, Ge L, O'Brien C, Haydu L, Honchell CD, Haverty PM, Peters BA, Wu TD, Amler LC, Chant J, Stokoe D, Lackner MR, Cavet G: Genetic alterations and oncogenic pathways associated with breast cancer subtypes. Mol Cancer Res 2009, 7:511-522.

23. GlaxoSmithKline Cancer Cell Line Genomic Profiling Data. [https://cabig. nci.nih.gov/tools/caArray_GSKdata].

24. Parker JS, Mullins M, Cheang MC, Leung S, Voduc D, Vickery T, Davies S, Fauron C, He X, Hu Z, Quackenbush JF, Stijleman IJ, Palazzo J, Marron JS, Nobel AB, Mardis E, Nielsen TO, Ellis MJ, Perou CM, Bernard PS: Supervised risk predictor of breast cancer based on intrinsic subtypes. J Clin Oncol 2009, 27:1160-1167.

25. Weigelt B, Mackay A, A'Hern R, Natrajan R, Tan DS, Dowsett M, Ashworth A, Reis-Filho JS: Breast cancer molecular profiling with single sample predictors: a retrospective analysis. Lancet Oncol 2010, 11:339-349.

26. Ringner M, Fredlund E, Hakkinen J, Borg A, Staaf J: GOBO: Gene Expression-Based Outcome for Breast Cancer Online. PLOS ONE 2011, 6: e17911.

27. Jonsson G, Staaf J, Olsson E, Heidenblad M, Vallon-Christersson J, Osoegawa K, de Jong P, Oredsson S, Ringner M, Hoglund M, Borg A: High- resolution genomic profiles of breast cancer cell lines assessed by tiling BAC array comparative genomic hybridization. Genes Chromosomes Cancer 2007, 46:543-558

28. Gene Expression Omnibus. [http://www.ncbi.nlm.nih.gov/geo/].

29. Bengtsson $H$, Wirapati $P$, Speed TP: A single-array preprocessing method for estimating full-resolution raw copy numbers from all Affymetrix genotyping arrays including GenomeWideSNP 5 \& 6. Bioinformatics 2009, 25:2149-2156.

30. Ortiz-Estevez M, Bengtsson $H$, Rubio A: ACNE: a summarization method to estimate allele-specific copy numbers for Affymetrix SNP arrays. Bioinformatics 2010, 26:1827-1833.

31. Hupe P, Stransky N, Thiery JP, Radvanyi F, Barillot E: Analysis of array CGH data: from signal ratio to gain and loss of DNA regions. Bioinformatics 2004, 20:3413-3422.

32. Olshen $A B$, Venkatraman ES, Lucito $R$, Wigler M: Circular binary segmentation for the analysis of array-based DNA copy number data. Biostatistics 2004, 5:557-572.

33. UCSC Genome Bioinformatics Browser. [http://genome.ucsc.edu/].

34. Gunnarsson R, Staaf J, Jansson M, Ottesen AM, Goransson H, Liljedahl U, Ralfkiaer U, Mansouri M, Buhl AM, Smedby KE, Hjalgrim H, Syvanen AC, Borg A, Isaksson A, Jurlander J, Juliusson G, Rosenquist R: Screening for copy-number alterations and loss of heterozygosity in chronic lymphocytic leukemia-A comparative study of four differently designed, high resolution microarray platforms. Genes Chromosomes Cancer 2008, 47:697-711.

35. Beroukhim R, Getz G, Nghiemphu L, Barretina J, Hsueh T, Linhart D, Vivanco I, Lee JC, Huang JH, Alexander S, Du J, Kau T, Thomas RK, Shah K, Soto H, Perner S, Prensner J, Debiasi RM, Demichelis F, Hatton C, Rubin MA, Garraway LA, Nelson SF, Liau L, Mischel PS, Cloughesy TF, Meyerson M, Golub TA, Lander ES, Mellinghoff IK, et al: Assessing the significance of chromosomal aberrations in cancer: methodology and application to glioma. Proc Natl Acad Sci USA 2007, 104:20007-20012.

36. Jonsson G, Staaf J, Vallon-Christersson J, Ringner M, Holm K, Hegardt C, Gunnarsson H, Fagerholm R, Strand C, Agnarsson BA, Kilpivaara O, Luts L, Heikkila P, Aittomaki K, Blomqvist C, Loman N, Malmstrom P, Olsson H, Johannsson OT, Arason A, Nevanlinna H, Barkardottir RB, Borg A: Genomic subtypes of breast cancer identified by array-comparative genomic hybridization display distinct molecular and clinical characteristics. Breast Cancer Res 2010, 12:R42.

37. Baldetorp B, Dalberg M, Holst U, Lindgren G: Statistical evaluation of cell kinetic data from DNA flow cytometry (FCM) by the EM algorithm. Cytometry 1989, 10:695-705.

38. Bagwell CB, Clark GM, Spyratos F, Chassevent A, Bendahl PO, Stal O, Killander D, Jourdan ML, Romain S, Hunsberger B, Baldetorp B: Optimizing flow cytometric DNA ploidy and S-phase fraction as independent prognostic markers for node-negative breast cancer specimens. Cytometry 2001, 46:121-135.

39. Campbell LL, Polyak K: Breast tumor heterogeneity: cancer stem cells or clonal evolution? Cell Cycle 2007, 6:2332-2338.

40. Navin N, Kendall J, Troge J, Andrews P, Rodgers L, Mclndoo J, Cook K, Stepansky A, Levy D, Esposito D, Muthuswamy L, Krasnitz A, McCombie WR, Hicks J, Wigler M: Tumour evolution inferred by single-cell sequencing. Nature 2011, 472:90-94.

41. Axelson H, Fredlund E, Ovenberger M, Landberg G, Pahlman S: Hypoxiainduced dedifferentiation of tumor cells-a mechanism behind heterogeneity and aggressiveness of solid tumors. Semin Cell Dev Biol 2005, 16:554-563.

42. LaFramboise T, Weir BA, Zhao X, Beroukhim R, Li C, Harrington D, Sellers WR, Meyerson M: Allele-specific amplification in cancer revealed by SNP array analysis. PLOS Comput Biol 2005, 1:e65.

43. Liu F, Lang R, Zhao J, Zhang X, Pringle GA, Fan Y, Yin D, Gu F, Yao Z, Fu L: $\mathrm{CD} 8(+)$ cytotoxic $T$ cell and FOXP3(+) regulatory $T$ cell infiltration in relation to breast cancer survival and molecular subtypes. Breast Cancer Res Treat 2011.

44. Mahmoud SM, Paish EC, Powe DG, Macmillan RD, Grainge MJ, Lee AH, Ellis IO, Green AR: Tumor-infiltrating CD8+ lymphocytes predict clinical outcome in breast cancer. J Clin Oncol 2011, 29:1949-1955.

45. Alexe G, Dalgin GS, Scanfeld D, Tamayo P, Mesirov JP, DeLisi C, Harris L, Barnard N, Martel M, Levine AJ, Ganesan S, Bhanot G: High expression of lymphocyte-associated genes in node-negative HER2+ breast cancers correlates with lower recurrence rates. Cancer Res 2007, 67:10669-10676. 
46. Zhuang Z, Park WS, Pack S, Schmidt L, Vortmeyer AO, Pak E, Pham T, Weil RJ, Candidus S, Lubensky IA, Linehan WM, Zbar B, Weirich G: Trisomy 7-harbouring non-random duplication of the mutant MET allele in hereditary papillary renal carcinomas. Nat Genet 1998, 20:66-69.

47. Bianchi $A B$, Aldaz CM, Conti CJ: Nonrandom duplication of the chromosome bearing a mutated Ha-ras-1 allele in mouse skin tumors. Proc Natl Acad Sci USA 1990, 87:6902-6906.

48. Rajagopalan H, Lengauer C: Aneuploidy and cancer. Nature 2004, 432:338-341.

49. Chin K, DeVries S, Fridlyand J, Spellman PT, Roydasgupta R, Kuo WL, Lapuk A, Neve RM, Qian Z, Ryder T, Chen F, Feiler H, Tokuyasu T, Kingsley C, Dairkee S, Meng Z, Chew K, Pinkel D, Jain A, Ljung BM, Esserman L, Albertson DG, Waldman FM, Gray JW: Genomic and transcriptional aberrations linked to breast cancer pathophysiologies. Cancer Cell 2006, 10:529-541.

50. Bergamaschi A, Kim YH, Wang P, Sorlie T, Hernandez-Boussard T, Lonning PE, Tibshirani R, Borresen-Dale AL, Pollack JR: Distinct patterns of DNA copy number alteration are associated with different clinicopathological features and gene-expression subtypes of breast cancer. Genes Chromosomes Cancer 2006, 45:1033-1040.

doi:10.1186/bcr3075

Cite this article as: Staaf et al: Landscape of somatic allelic imbalances and copy number alterations in HER2-amplified breast cancer. Breast Cancer Research 2011 13:R129.

\section{Submit your next manuscript to BioMed Central and take full advantage of:}

- Convenient online submission

- Thorough peer review

- No space constraints or color figure charges

- Immediate publication on acceptance

- Inclusion in PubMed, CAS, Scopus and Google Scholar

- Research which is freely available for redistribution

Submit your manuscript at www.biomedcentral.com/submit 